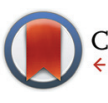

CrossMark \&lick for updates

Cite this: Dalton Trans., 2016, 45 8937

Received 1st April 2016,

Accepted 27th April 2016

DOI: $10.1039 / c 6 d t 01263 a$

www.rsc.org/dalton

\title{
Well-defined coinage metal transfer agents for the synthesis of NHC-based nickel, rhodium and palladium macrocycles $\uparrow$
}

\author{
Rhiann E. Andrew, Caroline M. Storey and Adrian B. Chaplin*
}

\begin{abstract}
With a view to use as carbene transfer agents, well-defined silver(I) and copper(I) complexes of a macrocyclic NHC-based pincer ligand, bearing a central lutidine donor and a dodecamethylene spacer [CNC$\left.\left(\mathrm{CH}_{2}\right)_{12}, 1\right]$, have been prepared. Although the silver adduct is characterised by X-ray diffraction as a dinuclear species anti-[Ag( $\mu-1)]_{2}{ }^{2+}$, variable temperature measurements indicate dynamic structural interchange in solution involving fragmentation into mononuclear $[\mathrm{Ag}(\mathbf{1})]^{+}$on the NMR time scale. In contrast, a mononuclear structure is evident in both solution and the solid-state for the analogous copper adduct partnered with the weakly coordinating $\left[\mathrm{BAr}_{4}\right]_{4}^{-}$counter anion. A related copper derivative, bearing instead the more coordinating cuprous bromide dianion $\left[\mathrm{Cu}_{2} \mathrm{Br}_{4}\right]^{2-}$, is notable for the adoption of an interesting tetranuclear assembly in the solid-state, featuring two cuprophilic interactions and two bridging NHC donors, but is not retained on dissolution. Coinage metal precursors $[\mathrm{M}(\mathbf{1})]_{n}\left[\mathrm{BAr}_{4}\right]_{n}(\mathrm{M}=\mathrm{Ag}, n=2 ; \mathrm{M}=\mathrm{Cu}, n=1)$ both act as carbene transfer agents to afford palladium, rhodium and nickel complexes of 1 and the effectiveness of these precursors has been evaluated under equivalent reaction conditions.
\end{abstract}

\section{Introduction}

The chemistry of N-heterocyclic carbene (NHC) complexes of the transition elements is rich, varied and at the forefront of contemporary organometallic chemistry and catalysis. ${ }^{1}$ While the formation of these adducts via direct coordination of the singlet carbene, isolated or generated in situ through deprotonation of the corresponding azolium salt, is conceptually the simplest method, the high chemical reactivity of these free carbene intermediates or incompatibility of the reaction conditions with acidic functionalities have necessitated the development of alternative approaches involving isolable 'protected' carbenes and transmetallation procedures. In this context, $\mathrm{Ag}(\mathrm{I})-\mathrm{NHC}$ complexes have proved to be effective carbene transfer agents for a wide variety of late-transition elements (Scheme 1). ${ }^{2-4}$ These reagents are conveniently formed through reaction of the respective pro-ligand NHC.HX with $\mathrm{Ag}_{2} \mathrm{O}$, resulting in mono- or bis-ligated complexes $[\mathrm{Ag}(\mathrm{NHC}) \mathrm{X}]$ or $\left[\mathrm{Ag}(\mathrm{NHC})_{2}\right] \mathrm{X}$ depending on the nature of the anion $(\mathrm{X}){ }^{2,3}$ Although comparatively less common, $\mathrm{Cu}(\mathrm{I})-\mathrm{NHC}$ complexes

Department of Chemistry, University of Warwick, Gibbet Hill Road,

CoventryCV4 7AL, UK. E-mail: a.b.chaplin@warwick.ac.uk

$\dagger$ Electronic supplementary information (ESI) available: ${ }^{1} \mathrm{H}$ and ${ }^{13} \mathrm{C}\left\{{ }^{1} \mathrm{H}\right\} \mathrm{NMR}$, and ESI-MS spectra of new complexes. Selected ${ }^{1} \mathrm{H}$ NMR data for transmetallation reactions of 2 and 4. CCDC 1470494-1470497. For ESI and crystallographic data in CIF or other electronic format see DOI: 10.1039/c6dt01263a have also been employed as carbene transfer agents (Scheme 1). ${ }^{2,5}$ Such copper reagents can be prepared from reactions between $\mathrm{Cu}_{2} \mathrm{O}$ and $\mathrm{NHC} \cdot \mathrm{HX}$, but are generally prepared via free carbene intermediates. ${ }^{2}$ Interestingly, reflecting the relative $\mathrm{M}(\mathrm{I})-\mathrm{NHC}$ bond strengths of the coinage metals $(\mathrm{Au}>\mathrm{Cu}>\mathrm{Ag}),{ }^{6}$ transmetallation of both silver and copper complexes can be used to prepare gold derivatives as a result of the more robust nature of $\mathrm{Au}(\mathrm{I})-\mathrm{NHC}$ bonds. ${ }^{2-5}$

The application of carbene transfer methodology is not limited to monodentate examples and the use of silver-based transmetallation protocols is also prevalent in the coordination chemistry of mer-tridentate "pincer" ligands bearing terminal NHC donors. ${ }^{7,8}$ While the corresponding silver transfer agents are often generated in situ, well defined and characteristically bimetallic $\mathrm{Ag}(\mathrm{I})-\mathrm{CEC}(\mathrm{E}=\mathrm{C}, \mathrm{N})$ complexes such as A-C have been isolated and crystallographically characterised (Scheme 2). ${ }^{9-15}$ Copper adducts of CEC $(\mathrm{E}=\mathrm{C}, \mathrm{N})$ ligands have also been prepared (e.g. D and E),$^{10,16-18}$ however, their application as transfer agents has yet to be realised to our knowledge.

As part of our work involving the organometallic chemistry of macrocyclic CNC pincers, ${ }^{19}$ we now report the synthesis and characterisation of well-defined $\mathrm{Ag}(\mathrm{I})$ and $\mathrm{Cu}(\mathrm{I})$ adducts of a lutidine-based pincer ligand bearing a dodecamethylene spacer $\left[\mathrm{CNC}-\left(\mathrm{CH}_{2}\right)_{12}, 1\right]$. The use of these coinage metal species as transfer agents is then detailed for the synthesis of rhodium, palladium, and nickel complexes of $\mathbf{1}$. 


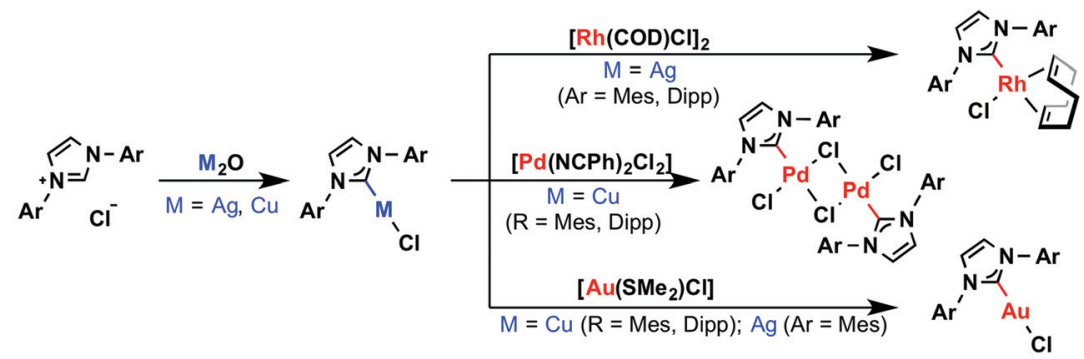

Scheme 1 Selected synthesis and reactions of $\mathrm{Cu}(1)$ and $\mathrm{Ag}(1)-\mathrm{NHC}$ complexes. ${ }^{4,5}$
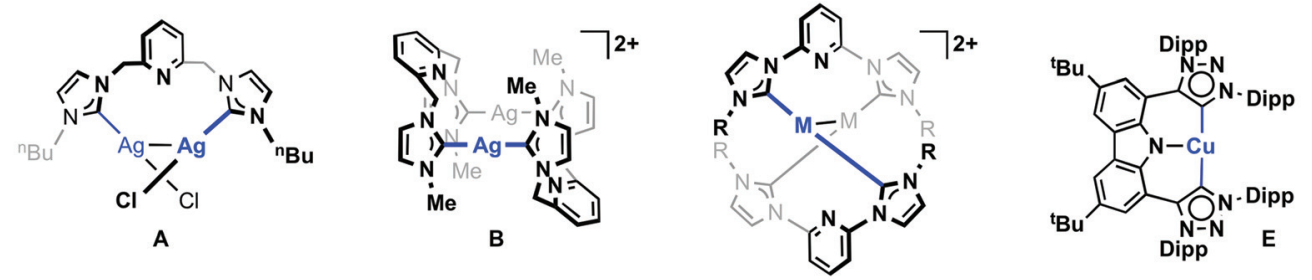

$\left(\mathrm{M}=\mathrm{Ag}, \mathrm{C} ; \mathrm{Cu}, \mathrm{D} ; \mathrm{R}={ }^{\mathrm{n}} \mathrm{Bu},{ }^{\mathrm{B}} \mathrm{Bu}\right)$

Scheme 2 Examples of isolated $\mathrm{Ag}(\mathrm{I})$ and $\mathrm{Cu}(\mathrm{I})$ complexes of $\mathrm{CNC}$ pincer ligands. ${ }^{12-17}$

\section{Results and discussion}

Our preceding work exploring the coordination chemistry of $\mathbf{1}$ employed in situ generation of silver transfer agents from the reaction between $1 \cdot 2 \mathrm{HBr}$ and $\mathrm{Ag}_{2} \mathrm{O}$ in $\mathrm{CH}_{2} \mathrm{Cl}_{2}$ solution. ${ }^{19}$ As a convenient means of incorporating a weakly coordinating $\left[\mathrm{BAr}_{4}^{\mathrm{F}}\right]^{-}$anion ${ }^{20}$ and conferring solution solubility, these reactions were carried out in the presence of $\mathrm{Na}\left[\mathrm{BAr}_{4}^{\mathrm{F}}\right]\left(\mathrm{Ar}^{\mathrm{F}}=3,5\right.$ $\left.\mathrm{C}_{6} \mathrm{H}_{3}\left(\mathrm{CF}_{3}\right)_{2}\right)$ as halogen ion abstractor. Using a slightly adapted protocol to facilitate isolation, well-defined silver derivative 2 was prepared via reaction in diethyl ether (Scheme 3). Filtration to remove insoluble silver and sodium bromide salts, and subsequent recrystallization from $\mathrm{CHCl}_{3} /$ pentane, afforded analytically pure 2 as a white powder in reproducibly high isolated yields of $c a$. $80 \%$.

Single crystals grown from diethyl ether/pentane and analysed by X-ray crystallography enabled structural elucidation of 2 in the solid-state as a dinuclear complex anti-
$[\mathrm{Ag}(\mu-\mathbf{1})]_{2}\left[\mathrm{BAr}_{4}^{\mathrm{F}}\right]_{2}$ (Fig. 1) - as for closely related precedents $\mathbf{B}, \mathbf{F}$ and $\mathbf{G} .{ }^{11,13}$ Interestingly, while the principle geometric metrics about silver in $\mathbf{2}$ are directly comparable to the aforementioned precedents (e.g. Ag-NHC = 2.088(4), 2.093(4) ̊, B; 2.077(3), $2.080(3) \AA$ A, 2; NHC-Ag-NHC $\left.=176.78(9)^{\circ}, \mathbf{B} ; 178.99(13)^{\circ}, 2\right)$, the ligand topology is significantly altered. At the heart of the structural difference is the adoption of near orthogonal NHC$\mathrm{Ag}-\mathrm{NHC}$ geometries in $2\left[\mathrm{~N} 25-\mathrm{C} 24-\mathrm{C} 18^{*}-\mathrm{N} 19^{*}=100.2(4)^{\circ}\right]$, in contrast to coplanar NHC-Ag-NHC arrangements observed in $\mathbf{B}, \mathbf{F}$ and $\mathbf{G}$. This change in geometry is presumably necessary to accommodate the long aliphatic chain and as a consequence results in a very large $\mathrm{Ag} \cdot \mathrm{Ag}^{*}$ separation [7.2732(6) cf. 3.7171(5), B; 3.538(2), F; 4.6636(7) А̊, G], precluding the adoption of any argentophilic interaction as seen in $\mathbf{A}$ and C. $^{12,14,15}$.

${ }^{1} \mathrm{H}$ and ${ }^{13} \mathrm{C}$ NMR data recorded in $\mathrm{CD}_{2} \mathrm{Cl}_{2}$ confirm the expected 1:1 ligand to anion ratio and reveal time averaged $C_{2 \mathrm{v}}$ symmetry for 2 at $298 \mathrm{~K}(500 \mathrm{MHz})$. Such high symmetry is

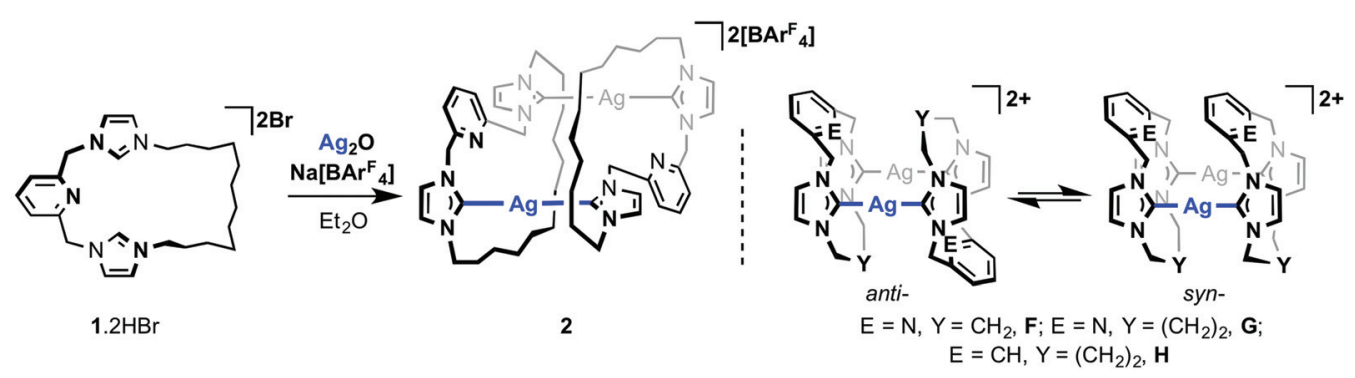

Scheme 3 Preparation of 2 and related literature precedents. ${ }^{11}$ 


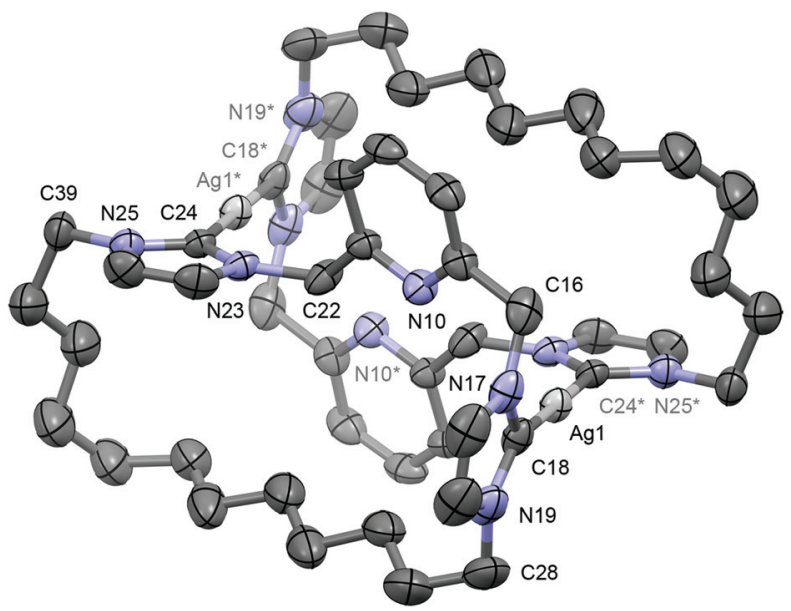

Fig. 1 Solid-state structure of 2. Thermal ellipsoids drawn at the $50 \%$ probability level; hydrogen atoms, minor disordered components and anions omitted for clarity. The starred atoms are generated by the symmetry operation $2-x, 1-y, 1-z$. Selected bond lengths $(\AA \AA)$ and angles $\left({ }^{\circ}\right.$ : : Ag1-C18, 2.077(3); Ag1-C24*, 2.080(3); Ag1‥Ag1*, 7.2732(6); C24-Ag1-C18*, 178.99(13); N25-C24-C18*-N19*, 100.2(4).

inconsistent with retention of the solid-state structure and instead implies highly fluxional behaviour in solution, involving fragmentation into $[\mathrm{Ag}(\mathbf{1})]^{+}(c f$. structure of $\mathbf{4}$ vide infra). Such an assertion is supported by ESI-MS, where only a singly charged species (i.e. integer mass spacing) was evident in the mass spectrum $\left([\operatorname{Ag}(1)]^{+}, 512.1927\right.$; calc. $\left.512.1938 \mathrm{~m} / \mathrm{z}\right)$. Not surprisingly the carbene signals of 2 were not observed by ${ }^{13} \mathrm{C}\left\{{ }^{1} \mathrm{H}\right\}$ NMR spectroscopy at $298 \mathrm{~K}$, although a chemical shift of $c a$. $\delta 181 \mathrm{ppm}$ can be inferred from 2D heteronuclear correlation experiments in line with expected values for $\mathrm{Ag}(\mathrm{I})-\mathrm{NHC}$ complexes. ${ }^{2,3 b, 21}$ Progressive cooling to $250 \mathrm{~K}$ lead to decoalescence of the (broadened) ${ }^{1} \mathrm{H}$ signals of 2 observed in $\mathrm{CD}_{2} \mathrm{Cl}_{2}$ at $298 \mathrm{~K}$ and establishment of an equilibrium mixture comprised of three major compounds, one of $C_{2 \mathrm{v}}$ symmetry and two of apparent $C_{\mathrm{s}}$ symmetry $(1: 0.5: 1)$. These species are tentatively assigned as $[\operatorname{Ag}(\mathbf{1})]^{+}$, syn- $[\operatorname{Ag}(\mu-\mathbf{1})]_{2}{ }^{2+}$ and anti-[Ag( $\left.(\mu-\mathbf{1})\right]_{2}{ }^{2+}$, respectively, on the basis of related behaviour observed for $\mathbf{F}$ and $\mathbf{G}$ involving rapid equilibration between syn- and antiisomers in solution (Scheme 3); dynamics that necessitate AgNHC bond cleavage and invoke coordination of the central lutidine donor through comparison to the less fluxional $m$-xylylene bridged analogue $\mathbf{H} .{ }^{11}$ In the case of 2 , the NMR data suggests that incorporation of the long dodecamethylene spacer destabilises the dinuclear structures relative to entropically favored fragmentation into $[\mathrm{Ag}(\mathbf{1})]^{+}$at ambient temperature. ${ }^{22}$ Further cooling to $200 \mathrm{~K}$ resulted in a shift in the equilibrium toward the species assigned to anti-[Ag( $(\mu-1)]_{2}{ }^{2+}$ (ca. 60\%) consistent with the pseudo $C_{\mathrm{i}}$ symmetric structure observed in the solid-state being enthalpically favoured in solution. In the context of 2 being used as a carbene transfer agent, these NMR data ultimately demonstrate facile $\mathrm{Ag}-\mathrm{NHC}$ bond cleavage under conditions relevant to synthesis of other transition metal adducts of $\mathbf{1}$ via transmetallation.

The synthesis of copper adducts of $\mathbf{1}$ was targeted by low temperature deprotonation of $1 \cdot 2 \mathrm{HBr}$ in THF in the presence of excess copper bromide. In this manner $[\mathrm{Cu}(\mathbf{1})]_{2}\left[\mathrm{Cu}_{2} \mathrm{Br}_{4}\right] 3$ was formed and subsequently isolated in $76 \%$ yield (Scheme 4). Further treatment of 3 with $\mathrm{Na}\left[\mathrm{BAr}_{4}^{\mathrm{F}}\right]$ in toluene resulted in incorporation of the weakly coordinating $\left[\mathrm{BAr}_{4}^{\mathrm{F}}\right]^{-}$ anion in place of $\left[\mathrm{Cu}_{2} \mathrm{Br}_{4}\right]^{2-}$ to afford 4 in $59 \%$ isolated yield. ${ }^{20,23}$ In $\mathrm{CD}_{2} \mathrm{Cl}_{2}$ solution, the ${ }^{1} \mathrm{H}$ and ${ }^{13} \mathrm{C}$ NMR characteristics of both 3 and 4 point towards simple mononuclear complexes of $\mathbf{1}$, with sharp resonances and apparent $C_{2 \mathrm{v}}$ symmetry in the respective spectra at $298 \mathrm{~K}(400 \mathrm{MHz})$. Moreover, only minor differences in chemical shift are found for the equivalent ${ }^{1} \mathrm{H}(<0.15 \mathrm{ppm})$ and ${ }^{13} \mathrm{C}(<2 \mathrm{ppm})$ signals of $3 / 4$, and presumably attributed to greater ion pairing in $\mathbf{3}$. Of most relevance to the coordination of $\mathbf{1}$, the carbenic centres were readily identified from ${ }^{13} \mathrm{C}\left\{{ }^{1} \mathrm{H}\right\}$ NMR spectra by their characteristically high frequency chemical shifts $(\delta 178.7,3 ; \delta 180.3,4){ }^{2}$ Strong parent cation signals are observed by ESI-MS with correct isotope patterns and integer mass spacing $(468.2185,3$; 468.2186 , 4; calc. $468.2183 \mathrm{~m} / \mathrm{z}$ ), further supporting the presence of discrete $[\mathrm{Cu}(\mathbf{1})]^{+}$in solution, irrespective of the counter anion.

Despite similar solution characteristics, in the solid-state the nature of the counter anion impacts significantly on the coordination geometries of 3 and 4 (Fig. 2 and 3). Two independent, but well-separated cation/anion pairs are observed in the solid-state structure of 4 . The cationic fragments are structurally similar, displaying near ideal T-shaped coordination geometries with the flexible dodecamethylene spacer notably skewed to one side. Focusing on the metrics associated with the independent cation shown in Fig. $2,{ }^{24}$ the complex displays an approximately linear $\mathrm{NHC}-\mathrm{Cu}-\mathrm{NHC}$ angle $\left(176.37(13)^{\circ}\right)$, equivalent $\mathrm{Cu}-\mathrm{NHC}$ bond lengths within error (1.905(3)/ 1.906(3) $\AA$ ), and a $\mathrm{Cu}-\mathrm{N}$ bond length of 2.233(3) $\AA$. These para-

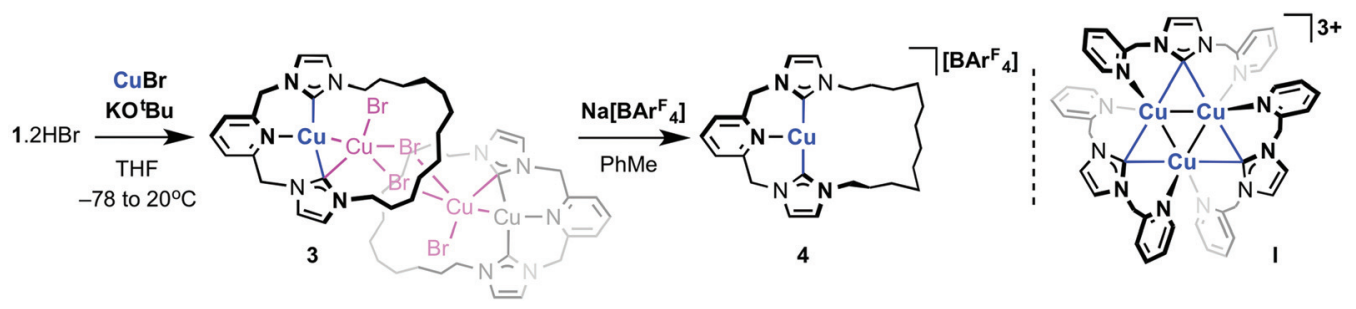

Scheme 4 Preparation of 3,4 and a related literature precedent. ${ }^{25}$ 


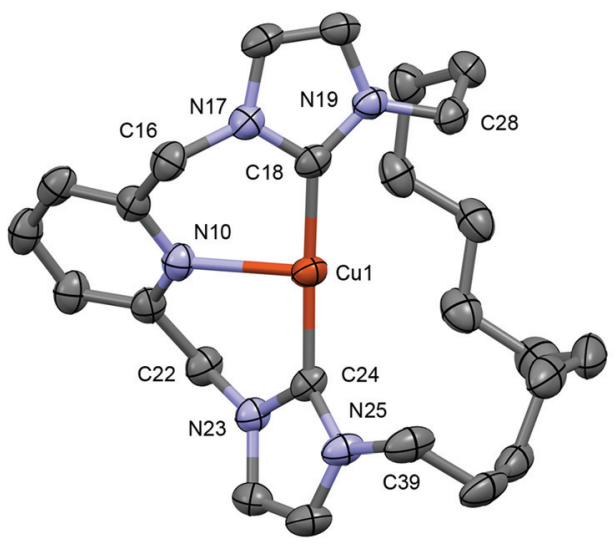

Fig. 2 Solid-state structure of 4 . Thermal ellipsoids drawn at the $50 \%$ probability level; only one of the unique cations shown $\left(Z^{\prime}=2\right)$ and hydrogen atoms omitted for clarity. Selected bond lengths $(\AA)$ and angles ('): Cu1-N10, 2.233(3); Cu1-C18, 1.905(3); Cu1-C24, 1.906(3); C18-Cu1-C24, 176.37(13).

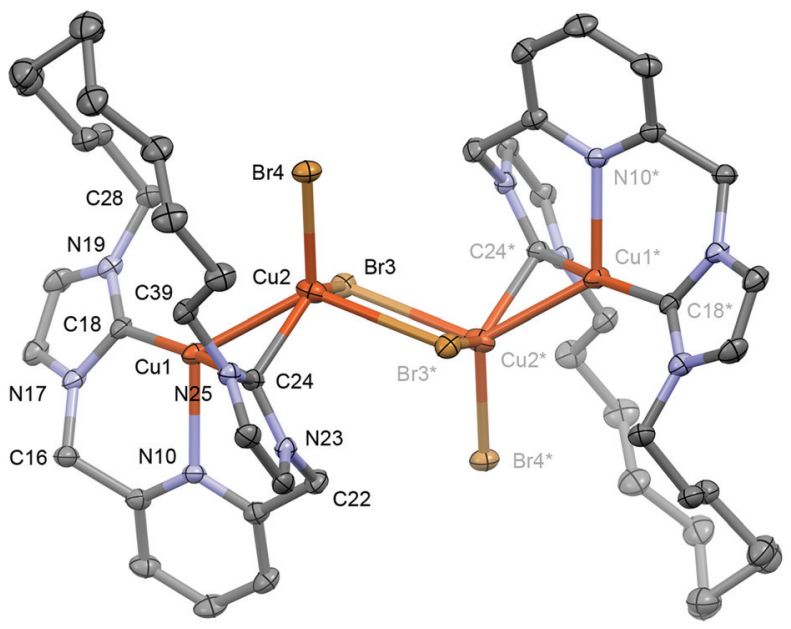

Fig. 3 Solid-state structure of 3 . Thermal ellipsoids drawn at the $50 \%$ probability level; hydrogen atoms omitted for clarity. The starred atoms are generated by the symmetry operation $1-x, 1-y, 1-z$. Selected bond lengths $(\AA)$ and angles $\left({ }^{\circ}\right)$ : Cu1-Cu2, 2.5209(5); Cu1-N10, 2.246(2); Cu1-C18, 1.925(3); Cu1-C24, 1.980(3); Cu2-Br3, 2.4583(4); Cu2-Br3*, 2.7728(5); Cu2-Br4, 2.4149(4); Cu2-C24, 2.070(3); Cu2-Br3-Cu2*, 83.794(15); Br3-Cu2-Br3*, 96.206(15); Cu1-Cu2-C24, 49.92(7); C18Cu1-C24, 167.92(11).

meters are in good agreement with those reported for $\mathbf{E}$, although the anionic nature of the component CNC pincer ligand leads to a shorter $\mathrm{Cu}-\mathrm{N}$ bond length than that in $\mathbf{4}$ $(2.017(2) \AA)$. In the case of 3 , an anion bridged dimer/tetranuclear formulation is instead observed, viz $[\mathrm{Cu}(\mathbf{1})]_{2}\left\{\mu-\left[\mathrm{Cu}_{2} \mathrm{Br}_{4}\right]\right\}$, featuring two formally bridging NHC donors (Cu1-C24, 1.980 (3); Cu2-C24, 2.070(3) ̊) and two cuprophilic interactions ( $\mathrm{Cu}-\mathrm{Cu}, 2.5209(5) \AA)$. The bonding interaction with the anion results in a significant distortion of the coordination geometry observed in 4, with the NHC-Cu-NHC angle deviating from line- arity $\left(167.92(11)^{\circ}\right)$ alongside elongation of the non-bridged $\mathrm{Cu}-$ NHC (1.925(3) cf. 1.905(3)/1.906(3) ̊) and Cu-N (Cu-N = 2.246(2) $c f$. 2.233(3)) bonds. The bridging $\mu^{2}$-NHC coordination mode is an unusual feature of 3 , but has striking precedence in trinuclear copper clusters, such as $\mathbf{I}$, that contain three ligands in this coordination mode (Cu-NHC ca. 2.026(5)-2.044(5) A for I). ${ }^{25,26}$ In these trinuclear clusters, the bridging coordination mode is retained in solution and characterised by $\delta_{13 \mathrm{C}} 167-169$ for imidazolyline based variants; values to significantly lower frequency than found for $3\left(\delta_{13 \mathrm{C}} 178.7\right){ }^{25,26}$

With well-defined coinage metal complexes 2 and 4 in hand, we turned to evaluation of their capacity to act as transfer agents of macrocyclic 1 in $\mathrm{CH}_{2} \mathrm{Cl}_{2}$. As convenient benchmarks we targeted preparation of known and soluble palladium and rhodium adducts of $1,[\mathrm{Pd}(\mathbf{1}) \mathrm{Cl}]\left[\mathrm{BAr}_{4}^{\mathrm{F}}\right] 5$ and $[\mathrm{Rh}(\mathbf{1})(\mathrm{CO})]\left[\mathrm{BAr}_{4}^{\mathrm{F}}\right]$ 6, through reactions with $\left[\mathrm{Pd}(\mathrm{NCMe})_{2} \mathrm{Cl}_{2}\right]$ and $\left[\mathrm{Rh}(\mathrm{CO})_{2} \mathrm{Cl}\right]_{2}$, respectively (Table 1). ${ }^{19 b, c}$ Following these reactions in situ by ${ }^{1} \mathrm{H}$ NMR spectroscopy in $\mathrm{CD}_{2} \mathrm{Cl}_{2}$, using the $\left[\mathrm{BAr}_{4}^{\mathrm{F}}\right]^{-}$resonances as a convenient internal standard, revealed rapid and high yielding transmetallation reactions of 2 in both cases ( $>70 \%$ yield). Consistent with these high yields, 5 and 6 have previously been isolated in 58\% and 52\% yield, respectively, through in situ generation of the silver transfer agent. ${ }^{19 b, c}$ In the case of copper, although complete consumption of $\mathbf{4}$ was apparent within $30 \mathrm{~min}$ in both cases, a large difference in selectivity is apparent: rhodium-based 6 was formed with an excellent yield of 98\% (and subsequently isolated in $82 \%$ yield), while palladium-based 5 was formed with a significantly inferior yield of $23 \%$.

Seeking to expand the scope of this transmetallation methodology, we targeted the preparation of nickel derivative 7 the lighter and Earth abundant group 10 congener of 5. Using

Table 1 Transmetallation reactions of 2 and $4^{a}$

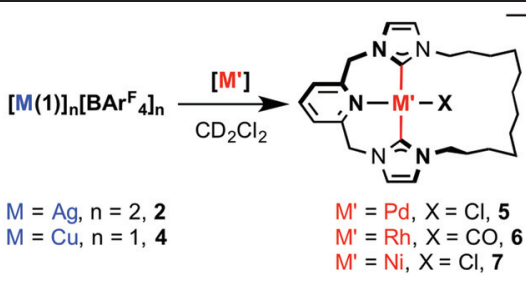

\begin{tabular}{llllll}
\hline$\left[\mathrm{M}^{\prime}\right]$ & $\mathrm{M}$ & $t^{b} / \mathrm{h}$ & $T /{ }^{\circ} \mathrm{C}$ & Product & Yield $^{c}$ \\
\hline$\left[\mathrm{Pd}(\mathrm{NCMe})_{2} \mathrm{Cl}_{2}\right]$ & $\mathrm{Ag}$ & 0.5 & 20 & $\mathbf{5}$ & $73 \%$ \\
{$\left[\mathrm{Pd}(\mathrm{NCMe})_{2} \mathrm{Cl}_{2}\right]$} & $\mathrm{Cu}$ & 0.5 & 20 & $\mathbf{5}$ & $23 \%$ \\
{$\left[\mathrm{Rh}(\mathrm{CO})_{2} \mathrm{Cl}\right]_{2}$} & $\mathrm{Ag}$ & 0.5 & 20 & $\mathbf{6}$ & $72 \%$ \\
{$\left[\mathrm{Rh}(\mathrm{CO})_{2} \mathrm{Cl}\right]_{2}$} & $\mathrm{Cu}$ & 0.5 & 20 & $\mathbf{6}$ & $98 \%$ \\
{$\left[\mathrm{NiCl}_{2}\right.$ (glyme) $]$} & $\mathrm{Ag}$ & $20^{d}$ & 20 & 7 & $22 \%$ \\
{$\left[\mathrm{NiCl}_{2}\right.$ (glyme) $]$} & $\mathrm{Ag}$ & 20 & 40 & 7 & $76 \%$ \\
{$\left[\mathrm{NiCl}_{2}\right.$ (glyme) $]$} & $\mathrm{Cu}$ & $20^{d}$ & 20 & 7 & $86 \%$ \\
{$\left[\mathrm{NiCl}_{2}\right.$ (glyme) $]$} & $\mathrm{Cu}$ & 5 & 40 & 7 & $90 \%$
\end{tabular}

${ }^{a}$ Reactions carried out in J. Young's NMR tubes, which were periodically placed in a ultrasound bath during the course of the reaction. ${ }^{b}$ Complete conversion unless otherwise noted. ${ }^{c}$ Determined by integration of ${ }^{1} \mathrm{H}$ NMR data. ${ }^{d}$ Incomplete reaction. 


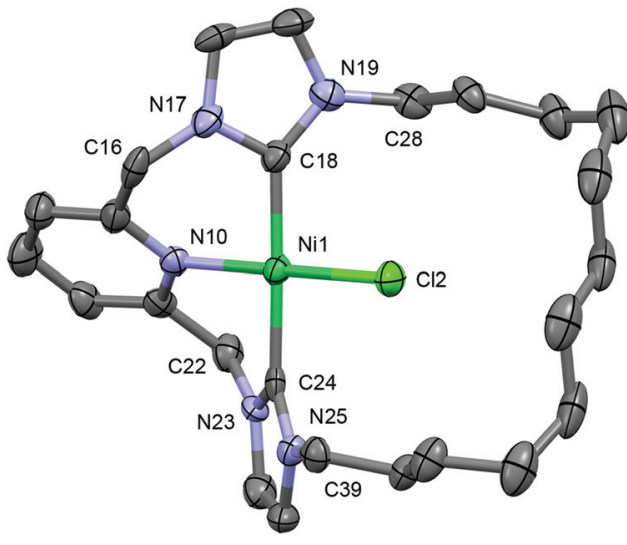

Fig. 4 Solid-state structure of 7. Thermal ellipsoids drawn at the 50\% probability level; hydrogen atoms and anion omitted for clarity. Selected bond lengths $(\AA \AA)$ and angles $\left({ }^{\circ}\right)$ : Ni1- $\mathrm{Cl} 2,2.145(2)$; Ni1-N10, 1.928(5); $\mathrm{Ni1}-\mathrm{C} 18,1.898(6) ; \mathrm{Ni1}-\mathrm{C} 24,1.916(6) ; \mathrm{N} 10-\mathrm{Ni1}-\mathrm{Cl} 2,179.06(15) ; \mathrm{C} 18-$ Ni1-C24, 176.6(3)

the aforementioned methodology in combination with $\left[\mathrm{NiCl}_{2}-\right.$ (glyme)], resulted in slow dissolution of the largely insoluble nickel(II) precursor, and gratifying (albeit gradual) formation of 7 at room temperature over 20 hours. The reaction with copper-based 4 notably proceeded $c a .4$ times faster, suggesting the explanation for this behaviour is more complex than low solubility of $\left[\mathrm{NiCl}_{2}\right.$ (glyme)] alone. Repeating under more forcing conditions $\left(40{ }^{\circ} \mathrm{C}\right)$ resulted in complete consumption of $2(20 \mathrm{~h})$ and $4(5 \mathrm{~h})$ and formation of 7 in $76 \%$ and $90 \%$ yield, respectively. The new air and moisture stable complex 7 was subsequently isolated from these reactions in ca. $30 \%$ yield following purification on alumina and fully characterised. Alternatively, 7 can also be prepared in similar yield using in situ generation of 2 from $1 \cdot 2 \mathrm{HBr}$ and $\mathrm{Ag}_{2} \mathrm{O}(29 \%$ isolated yield).

In the solid-state, 7 shows the expected contraction of metal-ligand bond lengths in comparison to 5 ( $\mathrm{Ni}-\mathrm{Cl}$, 2.145(2); Ni-N, 1.928(5); Ni-C, 1.898(6), 1.916(6) Аं; Pd-Cl, 2.287(4); Pd-N, 2.077(10); Pd-C, 2.036(12), 2.056(13) $\AA$ ), but is otherwise isostructural with the palladium-based analogue (Fig. 4) ${ }^{19 c}$ Most notably, the chloride ancillary ligand is easily accommodated within the macrocyclic ring, which is orientated to maintain pseudo $C_{2}$ symmetry ( $c f$. twisting observed in 4), with an essentially linear $\mathrm{N}-\mathrm{Ni}-\mathrm{Cl}$ bond angle (179.06(15) cf. $176.2(3)^{\circ}$ for the $\mathrm{N}-\mathrm{Pd}-\mathrm{Cl}$ angle in 5). In solution the solidstate structure is fully retained as indicated by the observation of diastereotopic methylene bridge $\left(\mathrm{pyCH}_{2}\right)$ and $N$-methylene $\left(N-\mathrm{CH}_{2} \mathrm{CH}_{2}\right)$ resonances at $\delta 5.14 / 6.30\left({ }^{2} J_{\mathrm{HH}}=15.0 \mathrm{~Hz}\right)$ and $\delta$ $3.73 / 4.73$, respectively. A single carbenic carbon signal is observed at $\delta 162.0(c f . \delta 164.5,5)$.

\section{Summary}

Well-defined silver(I) and copper(I) complexes of a macrocyclic NHC-based pincer ligand, bearing a central lutidine donor and a dodecamethylene spacer [CNC- $\left.\left(\mathrm{CH}_{2}\right)_{12}, \mathbf{1}\right]$, have been prepared. In the solid-state silver adduct 2 is characterised by X-ray diffraction as a dinuclear species anti- $[\operatorname{Ag}(\mu-1)]_{2}{ }^{2+}$, with the two metal centres held distant from each other $(\mathrm{Ag} \cdot \cdots \mathrm{Ag}$, $>7 \AA$ ) as a consequence of the conformation of the bridging macrocyclic ligand. However, variable temperature ${ }^{1} \mathrm{H}$ NMR spectroscopy indicates dynamic structural interchange in solution involving fragmentation into mononuclear $[\mathrm{Ag}(\mathbf{1})]^{+}$. In contrast, a mononuclear structure is evident in both solution and the solid-state for the analogous copper adduct $\mathbf{4}$ partnered with the weakly coordinating $\left[\mathrm{BAr}^{\mathrm{F}}{ }_{4}\right]^{-}$counter anion. A related copper derivative, bearing instead the more coordinating cuprous bromide dianion $\left[\mathrm{Cu}_{2} \mathrm{Br}_{4}\right]^{2-}$, is notable for the adoption of an interesting tetranuclear assembly in the solidstate, featuring two cuprophilic interactions $(\mathrm{Cu}-\mathrm{Cu}, 2.5209(5)$ $\AA)$ and two bridging NHC donors, but is not retained in solution. Coinage metal complexes $[\mathrm{M}(1)]_{n}\left[\mathrm{BAr}^{\mathrm{F}}\right]_{n}(\mathrm{M}=\mathrm{Ag}, n=2$, 2; $\mathrm{M}=\mathrm{Cu}, n=1,4)$ both act as carbene transfer agents to afford palladium (5), rhodium (6) and nickel complexes (7) of 1. Although not extensive, these reactions suggest that while silver-based transfer agents are more reliable, copper-based alternatives can result in significantly faster and higher yielding transmetallation reactions.

\section{Experimental}

\section{General experimental methods}

Manipulations were performed under an inert atmosphere, using Schlenk and glove box techniques unless otherwise stated. Glassware was oven dried and flamed under vacuum prior to use. Anhydrous solvents $\left(<0.005 \% \mathrm{H}_{2} \mathrm{O}\right)$ were purchased from ACROS or Aldrich and used as supplied: $\mathrm{Et}_{2} \mathrm{O}$, $\mathrm{CHCl}_{3}$, pentane, $\mathrm{CH}_{2} \mathrm{Cl}_{2}$, THF and toluene. $\mathrm{CD}_{2} \mathrm{Cl}_{2}$ was dried over molecular sieves $(4 \AA)$ and stored under an atmosphere of argon. $\mathrm{Na}\left[\mathrm{BAr}_{4}^{\mathrm{F}}\right],{ }^{27}\left[\mathrm{Rh}(\mathrm{CO})_{2} \mathrm{Cl}\right]_{2},{ }^{28}$ and $\mathbf{1} \cdot 2 \mathrm{HBr}^{19 c}$ were synthesised using literature procedures. All other reagents are commercial products and were used as received. NMR spectra were recorded on Bruker HD-300, DPX-400, AV-400, DRX-500 and AVIII-500 HD spectrometers at $298 \mathrm{~K}$ unless otherwise stated. Chemical shirts are quoted in ppm and coupling constants in Hz. ESI-MS were recorded on a Bruker MaXis mass spectrometer. Microanalyses were performed at the London Metropolitan University by Stephen Boyer.

\section{Synthesis of 2}

A mixture of $1 \cdot 2 \mathrm{HBr}(100 \mathrm{mg}, 0.176 \mathrm{mmol}), \mathrm{Ag}_{2} \mathrm{O}(42 \mathrm{mg}$, $0.181 \mathrm{mmol})$ and $\mathrm{Na}\left[\mathrm{BAr}_{4}^{\mathrm{F}}\right](170 \mathrm{mg}, 0.192 \mathrm{mmol})$ was suspended in $\mathrm{Et}_{2} \mathrm{O}(5 \mathrm{~mL})$ and stirred under argon in the absence of light for $48 \mathrm{~h}$. The resulting grey suspension was allowed to settle and the solution filtered through a celite plug (pipette, $3 \mathrm{~cm}$ ) under a flow of nitrogen. The colourless filtrate was concentrated to afford the crude product as white foam, which was subsequently dissolved in hot chloroform and filtered through a second celite plug (pipette, $3 \mathrm{~cm}$ ). The analytically pure product was obtained on addition of excess pentane, 
washed with pentane and dried. Yield: $200 \mathrm{mg}$ (82\%, white powder). Crystals suitable for X-ray diffraction were grown from ether/pentane at $20^{\circ} \mathrm{C}$.

${ }^{1} \mathbf{H}$ NMR $\left(400 \mathrm{MHz}, \mathrm{CD}_{2} \mathrm{Cl}_{2}\right) \delta 7.82$ (br, 1H, py), 7.70-7.75 $\left(\mathrm{m}, 8 \mathrm{H}, \mathrm{Ar}^{\mathrm{F}}\right.$ ), 7.56 (br, 4H, $\mathrm{Ar}^{\mathrm{F}}$ ), 7.42 (br, 2H, py), 7.17 (br, 2H, imid), 7.05 (s, 2H, imid), 5.25 (br, 4H, pyC${ }_{2}$ ), 4.06 (app. t, $J=$ 7, 4H, $\mathrm{NCH}_{2}$ ), 1.79 (app. pent., $J=7,4 \mathrm{H}, \mathrm{CH}_{2}$ ) 1.10-1.40 (m, $\left.16 \mathrm{H}, \mathrm{CH}_{2}\right) .{ }^{13} \mathrm{C}\left\{{ }^{1} \mathrm{H}\right\}$ NMR $\left(101 \mathrm{MHz}, \mathrm{CD}_{2} \mathrm{Cl}_{2}\right) \delta 162.3\left(\mathrm{q},{ }^{1} J_{\mathrm{CB}}=\right.$ 50, $\mathrm{Ar}^{\mathrm{F}}$ ), 155.1 (s, py), 140.5 (br, py), 135.4 (s, $\mathrm{Ar}^{\mathrm{F}}$ ), 129.4 (qq, $\left.{ }^{2} J_{\mathrm{FC}}=32,{ }^{3} J_{\mathrm{CB}}=3, \mathrm{Ar}^{\mathrm{F}}\right), 125.3\left(\mathrm{q},{ }^{1} J_{\mathrm{FC}}=273, \mathrm{Ar}^{\mathrm{F}}\right), 125.0(\mathrm{br}, \mathrm{py})$, 124.1 (br, imid), 120.2 (br, imid), 118.0 (pent., ${ }^{3} J_{\mathrm{FC}}=4, \mathrm{Ar}^{\mathrm{F}}$ ),

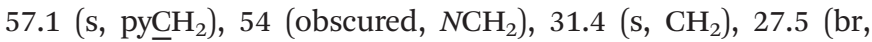
$\left.\mathrm{CH}_{2}\right), 25.8\left(\mathrm{~s}, \mathrm{CH}_{2}\right)$. The carbene resonance was not unambiguously identified in the ${ }^{13} \mathrm{C}\left\{{ }^{1} \mathrm{H}\right\}$ NMR spectrum, but can be located at ca. $\delta 181$ from an HMBC experiment. ESI-MS $\left(\mathrm{CH}_{3} \mathrm{CN}\right.$, $180{ }^{\circ} \mathrm{C}, 3 \mathrm{kV}$ ) positive ion: $512.1927 \mathrm{~m} / \mathrm{z},[\mathrm{M}]^{+}$(calc. 512.1938). Anal. Calcd for $\mathrm{C}_{57} \mathrm{H}_{47} \mathrm{AgBF}_{24} \mathrm{~N}_{5} \cdot \mathrm{CHCl}_{3}\left(1496.05 \mathrm{~g} \mathrm{~mol}^{-1}\right)$ : C, 46.28; H, 3.22; N, 4.64. Found: C, 46.08; H, 3.23; N, 4.58.

\section{Synthesis of 3}

A suspension of $\mathbf{1} \cdot 2 \mathrm{HBr}(200 \mathrm{mg}, 0.353 \mathrm{mmol})$ and $\mathrm{CuBr}$ (152 mg, $1.057 \mathrm{mmol}$ ) in THF (7 mL) under argon was cooled to $-78{ }^{\circ} \mathrm{C}$ before addition of a solution of $\mathrm{KO}^{t} \mathrm{Bu}(100 \mathrm{mg}$, $0.881 \mathrm{mmol})$ in THF ( $2 \mathrm{~mL})$ via cannula. The resulting orange suspension was warmed to room temperature and sonicated to produce a yellow suspension, which was stirred for a further $30 \mathrm{~h}$. The reaction mixture was filtered and the product precipitated by addition of excess pentane, isolated by filtration, washed with pentane and dried. Yield: $147 \mathrm{mg}$ (76\%, yellow powder). Crystals suitable for X-ray diffraction were grown from $\mathrm{CD}_{2} \mathrm{Cl}_{2} /$ pentane at $20^{\circ} \mathrm{C}$.

${ }^{1} \mathbf{H}$ NMR (400 MHz, $\left.\mathrm{CD}_{2} \mathrm{Cl}_{2}\right) \delta 7.78\left(\mathrm{t},{ }^{3} J_{\mathrm{HH}}=7.7,1 \mathrm{H}, \mathrm{py}\right)$, $7.39\left(\mathrm{~d},{ }^{3} J_{\mathrm{HH}}=7.7,2 \mathrm{H}, \mathrm{py}\right), 7.22\left(\mathrm{~d},{ }^{3} J_{\mathrm{HH}}=1.7,2 \mathrm{H}, \mathrm{imid}\right), 6.98$ $\left(\mathrm{d},{ }^{3} J_{\mathrm{HH}}=1.7,2 \mathrm{H}\right.$, imid), $5.37\left(\mathrm{~s}, 4 \mathrm{H}, \mathrm{pyC}_{2}\right), 4.17\left(\mathrm{t},{ }^{3} J_{\mathrm{HH}}=\right.$ 6.8, $4 \mathrm{H}, \mathrm{NCH}_{2}$ ), 1.83 (app. pent., $J=7,4 \mathrm{H}, \mathrm{CH}_{2}$ ), 1.14-1.34 (m, $\left.16 \mathrm{H}, \mathrm{CH}_{2}\right) .{ }^{13} \mathrm{C}\left\{{ }^{1} \mathrm{H}\right\}$ NMR $\left(101 \mathrm{MHz}, \mathrm{CD}_{2} \mathrm{Cl}_{2}\right) \delta 178.7$ (s, NCN), 155.5 (s, py), 139.4 (s, py), 123.2 (s, py), 122.5 (s, imid), 120.8 (s, imid), $56.3\left(\mathrm{~s}, \mathrm{pyCH}_{2}\right), 52.1\left(\mathrm{~s}, \mathrm{NCH}_{2}\right), 31.2\left(\mathrm{~s}, \mathrm{CH}_{2}\right), 28.1$ (s, $\left.\mathrm{CH}_{2}\right), 27.8\left(\mathrm{~s}, \mathrm{CH}_{2}\right), 25.8\left(\mathrm{~s}, \mathrm{CH}_{2}\right)$. ESI-MS $\left(\mathrm{CH}_{3} \mathrm{CN}, 180{ }^{\circ} \mathrm{C}\right.$, $3 \mathrm{kV}$ ) positive ion: $468.2185 \mathrm{~m} / \mathrm{z},[\mathrm{M}]^{+}$(Calc. 468.2183). Anal. Calcd for $\mathrm{C}_{50} \mathrm{H}_{70} \mathrm{Br}_{4} \mathrm{Cu}_{4} \mathrm{~N}_{10} \quad\left(1384.96 \mathrm{~g} \mathrm{~mol}{ }^{-1}\right)$ : C, 43.36; H, 5.09; N, 10.11. Found: C, 43.28; H, 4.97; N, 9.99.

\section{Synthesis of 4}

A suspension of 3 (53 mg, $0.0383 \mathrm{mmol}$ ) and $\mathrm{Na}\left[\mathrm{BAr}^{\mathrm{F}}{ }_{4}\right]$ (90 $\mathrm{mg}, 0.1016 \mathrm{mmol}$ ) was sonicated in toluene $(3 \mathrm{~mL})$ and then stirred at room temperature for 2 days before filtration. The filtrate was concentrated to dryness and the crude product crystallised from THF/pentane. Yield: $62 \mathrm{mg}$ (61\%, pale yellow powder) as $4 \cdot 0.5 \mathrm{THF}$. Crystals suitable for X-ray diffraction were grown from ether/pentane at $20^{\circ} \mathrm{C}$.

${ }^{1} \mathrm{H}$ NMR (400 MHz, $\left.\mathrm{CD}_{2} \mathrm{Cl}_{2}\right) \delta 7.83\left(\mathrm{t},{ }^{3} J_{\mathrm{HH}}=7.8,1 \mathrm{H}, \mathrm{py}\right)$, $7.73\left(\mathrm{bs}, 8 \mathrm{H}, \mathrm{Ar}^{\mathrm{F}}\right), 7.56\left(\mathrm{br}, 4 \mathrm{H}, \mathrm{Ar}^{\mathrm{F}}\right), 7.42\left(\mathrm{~d},{ }^{3} J_{\mathrm{HH}}=7.8,2 \mathrm{H}\right.$, py), $7.10\left(\mathrm{~d},{ }^{3} \mathrm{~J}_{\mathrm{HH}}=1.2,2 \mathrm{H}\right.$, imid), $7.02\left(\mathrm{~d},{ }^{3} J_{\mathrm{HH}}=1.2,2 \mathrm{H}\right.$, imid), $5.19\left(\mathrm{~s}, 4 \mathrm{H}, \mathrm{pyCH}_{2}\right), 4.20\left(\mathrm{t},{ }^{3} \mathrm{~J}_{\mathrm{HH}}=7.6,4 \mathrm{H}, \mathrm{NCH}_{2}\right), 1.87$ (app. pent., $\left.J=7,4 \mathrm{H}, \mathrm{CH}_{2}\right), 1.25-1.48\left(\mathrm{~m}, 16 \mathrm{H}, \mathrm{CH}_{2}\right) .{ }^{13} \mathrm{C}\left\{{ }^{1} \mathbf{H}\right\}$
NMR (101 MHz, $\left.\mathrm{CD}_{2} \mathrm{Cl}_{2}\right) \delta 180.3(\mathrm{~s}, \mathrm{NCN}), 162.3\left(\mathrm{q},{ }^{1} J_{\mathrm{CB}}=50\right.$, $\operatorname{Ar}^{\mathrm{F}}$ ), 153.8 (s, py), 140.2 (s, py), $135.4\left(\mathrm{~s}, \mathrm{Ar}^{\mathrm{F}}\right), 129.5\left(\mathrm{qq},{ }^{2} J_{\mathrm{FC}}=\right.$ $\left.32,{ }^{3} J_{\mathrm{CB}}=3, \mathrm{Ar}^{\mathrm{F}}\right), 125.2\left(\mathrm{q},{ }^{1} J_{\mathrm{FC}}=271, \mathrm{Ar}^{\mathrm{F}}\right), 124.1(\mathrm{~s}, \mathrm{py}), 123.2$ (s, imid), 119.6 (s, imid), 118.1 (pent., ${ }^{3} \mathrm{~J}_{\mathrm{FC}}=4, \mathrm{Ar}^{\mathrm{F}}$ ), 54.9 (s, pyㅡㄴ $\left.{ }_{2}\right), 52.9\left(\mathrm{~s}, \mathrm{NCH}_{2}\right), 31.4\left(\mathrm{~s}, \mathrm{CH}_{2}\right), 27.2\left(\mathrm{~s}, \mathrm{CH}_{2}\right), 27.1(\mathrm{~s}$, $\left.\mathrm{CH}_{2}\right), 25.8\left(\mathrm{~s}, \mathrm{CH}_{2}\right), 25.6\left(\mathrm{~s}, \mathrm{CH}_{2}\right)$. ESI-MS $\left(\mathrm{CH}_{3} \mathrm{CN}, 180{ }^{\circ} \mathrm{C}\right.$, $3 \mathrm{kV}$ ) positive ion: $468.2185 \mathrm{~m} / \mathrm{z},[\mathrm{M}]^{+}$(Calc. 468.2183). Anal. Calcd for $\mathrm{C}_{57} \mathrm{H}_{47} \mathrm{BCuF}_{24} \mathrm{~N}_{5}\left(1332.33 \mathrm{~g} \mathrm{~mol}^{-1}\right)$ : C, 51.38; H, 3.56; N, 5.26. Found: C, 51.48; H, 3.47; N, 5.34.

\section{In situ formation of 5 and 6}

A J. Young's NMR tube was charged with $0.004 / 0.008 \mathrm{mmol}$ of 2/4 and 1.1 equivalent (metal per metal) of $\left[\mathrm{Pd}(\mathrm{NCMe})_{2} \mathrm{Cl}_{2}\right] /$ $\left[\mathrm{Rh}(\mathrm{CO})_{2} \mathrm{Cl}\right]_{2} \cdot \mathrm{CD}_{2} \mathrm{Cl}_{2}(0.5 \mathrm{~mL})$ was added and the reaction monitored by ${ }^{1} \mathrm{H}$ NMR until complete consumption of $2 / 4$. The samples were periodically placed in an ultrasound bath during the course of the reaction. In the case of the reaction between 4 and $\left[\mathrm{Rh}(\mathrm{CO})_{2} \mathrm{Cl}\right]_{2}$, the crude reaction mixture was subsequently passed through a short silica plug (pipette, $3 \mathrm{~cm}$ ) with additional $\mathrm{CH}_{2} \mathrm{Cl}_{2}$ to afford 6 in $82 \%$ yield following removal of the solvent in vacuo.

\section{Synthesis of 7}

Following in situ reaction monitoring. A J. Young's NMR tube was charged with $0.004 / 0.008 \mathrm{mmol}$ of $2 / 4$ and 1.4 equivalent (metal per metal) of $\left[\mathrm{NiCl}_{2}\right.$ (gylme) $] . \mathrm{CD}_{2} \mathrm{Cl}_{2}(0.5 \mathrm{~mL})$ was added and the reaction monitored by ${ }^{1} \mathrm{H}$ NMR at either $20{ }^{\circ} \mathrm{C}$ or $40{ }^{\circ} \mathrm{C}$. The samples were periodically placed in an ultrasound bath during the course of the reaction. On complete consumption of $2 / 4$ at $40{ }^{\circ} \mathrm{C}$, the crude reaction mixture was passed through a short alumina plug (pipette, $3 \mathrm{~cm}$ ) with additional $\mathrm{CH}_{2} \mathrm{Cl}_{2}$ to afford 7 in $27 \% / 26 \%$ yield following removal of the solvent in vacuo.

Using in situ silver-based transmetallation reagent. A mixture of $1 \cdot 2 \mathrm{HBr}(100 \mathrm{mg}, 0.176 \mathrm{mmol}), \mathrm{Ag}_{2} \mathrm{O}$ (45 mg, $0.194 \mathrm{mmol}$ ) and $\mathrm{Na}\left[\mathrm{BAr}_{4}^{\mathrm{F}}\right]$ (172 mg, $\left.0.194 \mathrm{mmol}\right)$ was suspended in $\mathrm{CH}_{2} \mathrm{Cl}_{2}(3 \mathrm{~mL})$ and stirred under nitrogen in the absence of light for 20 hours. The resulting grey suspension was allowed to settle and the solution filtered into a flask charged with solid $\left[\mathrm{NiCl}_{2}\right.$ (glyme)] (40 mg, $0.182 \mathrm{mmol}$ ). After stirring the resulting suspension for $6 \mathrm{~h}$, the solution was passed through a short alumina plug (pipette, $3 \mathrm{~cm}$, washed with $\mathrm{CH}_{2} \mathrm{Cl}_{2}$ ) and the product obtained on removal of the volatiles in vacuo. Yield $=70 \mathrm{mg}$ (29\%, yellow powder). Crystals suitable for X-ray diffraction were grown from a mixture of toluene, diethylether, cyclohexane and pentane at $20^{\circ} \mathrm{C}$.

${ }^{1} \mathbf{H}$ NMR (500 MHz, $\left.\mathrm{CD}_{2} \mathrm{Cl}_{2}\right): \delta 7.82\left(\mathrm{t},{ }^{3} \mathrm{~J}_{\mathrm{HH}}=7.7,1 \mathrm{H}, \mathrm{py}\right)$, 7.68-7.76 (m, 8H, Ar $\left.{ }^{\mathrm{F}}\right), 7.55\left(\mathrm{br}, 4 \mathrm{H}, \mathrm{Ar}^{\mathrm{F}}\right), 7.45\left(\mathrm{~d},{ }^{3} J_{\mathrm{HH}}=7.7\right.$, $2 \mathrm{H}$, py), 7.11 (d, ${ }^{3} J_{\mathrm{HH}}=1.7,2 \mathrm{H}$, imid), 6.87 (d, ${ }^{3} J_{\mathrm{HH}}=1.7,2 \mathrm{H}$, imid), $6.30\left(\mathrm{~d},{ }^{2} J_{\mathrm{HH}}=15.0,2 \mathrm{H}, \mathrm{pyCH}_{2}\right), 5.14\left(\mathrm{~d},{ }^{2} J_{\mathrm{HH}}=15.0\right.$, $2 \mathrm{H}, \mathrm{pyCH}_{2}$ ), 4.73 (app. t $J=12,2 \mathrm{H}, \overline{N C H}_{2}$ ), 3.68-3.78 (m, $2 \mathrm{H}$, $\mathrm{NCH}_{2}$ ), 1.94 (br, 2H, $\mathrm{CH}_{2}$ ), 1.66 (br, 2H, $\mathrm{CH}_{2}$ ), 1.18-1.50 (m, $14 \mathrm{H}, \mathrm{CH}_{2}$ ), 1.09 (br, 2H, $\left.\mathrm{CH}_{2}\right) .{ }^{13} \mathbf{C}\left\{{ }^{1} \mathbf{H}\right\}$ NMR $(126 \mathrm{MHz}$, $\left.\mathrm{CD}_{2} \mathrm{Cl}_{2}\right): \delta 162.3\left(\mathrm{q},{ }^{1} J_{\mathrm{CB}}=50, \mathrm{Ar}^{\mathrm{F}}\right), 162.0(\mathrm{~s}, \mathrm{NCN}), 156.5(\mathrm{~s}, \mathrm{py})$, 140.9 (s, py), $135.3\left(\mathrm{~s}, \mathrm{Ar}^{\mathrm{F}}\right), 129.4\left(\mathrm{qq},{ }^{2} J_{\mathrm{FC}}=32,{ }^{3} J_{\mathrm{CB}}=3, \mathrm{Ar}^{\mathrm{F}}\right.$ ), $125.2\left(\mathrm{q},{ }^{1} J_{\mathrm{FC}}=271, \mathrm{Ar}^{\mathrm{F}}\right), 125.1(\mathrm{~s}, \mathrm{py}), 123.0(\mathrm{~s}, \mathrm{imid}), 121.4(\mathrm{~s}$, 
imid), 118.0 (pent., $\left.{ }^{3} J_{\mathrm{FC}}=4, \operatorname{Ar}^{\mathrm{F}}\right), 55.0\left(\mathrm{~s}, \mathrm{pyCH}_{2}\right), 51.3(\mathrm{~s}$, $\left.\mathrm{NCH}_{2}\right), 30.8\left(\mathrm{~s}, \mathrm{CH}_{2}\right), 28.7\left(\mathrm{~s}, \mathrm{CH}_{2}\right), 27.5\left(\mathrm{~s}, \mathrm{CH}_{2}\right), 23.7\left(\mathrm{~s}, \mathrm{CH}_{2}\right)$. ESI-MS $\left(\mathrm{CH}_{3} \mathrm{CN}, 180{ }^{\circ} \mathrm{C}, 4 \mathrm{kV}\right)$ positive ion: $498.1929 \mathrm{~m} / \mathrm{z},[\mathrm{M}]^{+}$ (calc. 498.1929). Anal. Calcd for $\mathrm{C}_{57} \mathrm{H}_{47} \mathrm{BClF}_{24} \mathrm{~N}_{5} \mathrm{Ni}(1362.95 \mathrm{~g}$ $\mathrm{mol}^{-1}$ ): C, 50.23; H, 3.48; N, 5.14. Found: C, 50.62; H, 3.74; N, 5.05 .

\section{Crystallography}

Full details about the collection, solution and refinement are documented in the CIF, which have been deposited with the Cambridge Crystallographic Data Centre under CCDC 1470494-1470497.

\section{Acknowledgements}

We thank the University of Warwick (R. E. A.), European Research Council (ERC, grant agreement 637313; C. M. S, A. B. C) and Royal Society (A. B. C.) for financial support. Crystallographic and high-resolution mass-spectrometry data were collected using instruments purchased through support from Advantage West Midlands and the European Regional Development Fund. Crystallographic data for 7 were collected using an instrument that received funding from the ERC under the European Union's Horizon 2020 research and innovation programme (grant agreement No 637313).

\section{References}

1 (a) M. N. Hopkinson, C. Richter, M. Schedler and F. Glorius, Nature, 2014, 510, 485-496; (b) M. Soleilhavoup and G. Bertrand, Acc. Chem. Res., 2015, 48, 256-266; (c) S. Díez-González, N. Marion and S. P. Nolan, Chem. Rev., 2009, 109, 3612-3676; (d) P. de Frémont, N. Marion and S. P. Nolan, Coord. Chem. Rev., 2009, 253, 862-892; (e) F. E. Hahn and M. C. Jahnke, Angew. Chem., Int. Ed., 2008, 47, 3122-3172.

2 J. C. Y. Lin, R. T. W. Huang, C. S. Lee, A. Bhattacharyya, W. S. Hwang and I. J. B. Lin, Chem. Rev., 2009, 109, 35613598.

3 (a) I. J. B. Lin and C. S. Vasam, Coord. Chem. Rev., 2007, 251, 642-670; (b) J. C. Garrison and W. J. Youngs, Chem. Rev., 2005, 105, 3978-4008.

4 (a) X.-Y. Yu, B. O. Patrick and B. R. James, Organometallics, 2006, 25, 2359-2363; (b) P. de Frémont, N. M. Scott, E. D. Stevens and S. P. Nolan, Organometallics, 2005, 24, 2411-2418.

5 M. R. L. Furst and C. S. J. Cazin, Chem. Commun., 2010, 46, 6924-6922.

6 C. Boehme and G. Frenking, Organometallics, 1998, 17, 5801-5809.

7 (a) R. E. Andrew, L. González-Sebastián and A. B. Chaplin, Dalton Trans., 2016, 45, 1299-1305; (b) M. Poyatos, J. A. Mata and E. Peris, Chem. Rev., 2009, 109, 3677-3707; (c) D. Pugh and A. A. Danopoulos, Coord. Chem. Rev., 2007,
251, 610-641; (d) E. Peris and R. H. Crabtree, Coord. Chem. Rev., 2004, 248, 2239-2246.

8 Representative examples of transmetallation reactions involving other polydentate NHC ligands: (a) D. T. Weiss, P. J. Altmann, S. Haslinger, C. Jandl, A. Pöthig, M. Cokoja and F. E. Kühn, Dalton Trans., 2015, 44, 18329-18339; (b) A. Rit, T. Pape and F. E. Hahn, J. Am. Chem. Soc., 2010, 132, 4572-4573; (c) F. E. Hahn, C. Radloff, T. Pape and A. Hepp, Chem. - Eur. J., 2008, 14, 10900-10904; (d) X. Hu, I. Castro-Rodriguez, K. Olsen and K. Meyer, Organometallics, 2004, 23, 755-764; (e) Y. A. Wanniarachchi, M. A. Khan and L. M. Slaughter, Organometallics, 2004, 23, 58815884 .

9 (a) J. Vaughan, D. J. Carter, A. L. Rohl, M. I. Ogden, B. W. Skelton, P. V. Simpson and D. H. Brown, Dalton Trans., 2016, 45, 1484-1495; (b) M. Hernández-Juárez, J. López-Serrano, P. Lara, J. P. Morales-Cerón, M. Vaquero, E. Álvarez, V. Salazar and A. Suárez, Chem. - Eur. J., 2015, 21, 7540-7555; (c) W. D. Clark, G. E. Tyson, T. K. Hollis, H. U. Valle, E. J. Valente, A. G. Oliver and M. P. Dukes, Dalton Trans., 2013, 42, 7338-7344; (d) S. Wei, X. Li, Z. Yang, J. Lan, G. Gao, Y. Xue and J. You, Chem. Sci., 2012, 3, 359-363; (e) K. Inamoto, J.-I. Kuroda, E. Kwon, K. Hiroya and T. Doi, J. Organomet. Chem., 2009, 694, 389-396; (f) D. H. Brown, G. L. Nealon, P. V. Simpson, B. W. Skelton and Z. Wang, Organometallics, 2009, 28, 1965-1968; (g) D. Pugh, A. Boyle and A. A. Danopoulos, Dalton Trans., 2008, 1087-1094; (h) W. Chen, B. Wu and K. Matsumoto, J. Organomet. Chem., 2002, 654, 233-236; (i) A. Caballero, E. Díez-Barra, F. A. Jalón, S. Merino, A. M. Rodríguez and J. Tejeda, J. Organomet. Chem., 2001, 627, 263-264.

10 (a) V. Charra, P. de Frémont, P.-A. R. Breuil, H. Olivier-Bourbigou and P. Braunstein, J. Organomet. Chem., 2015, 795, 25-33; X. Liu, R. Pattacini, P. Deglmann and P. Braunstein, Organometallics, 2011, 30, 3302-3310.

11 (a) A. Biffis, M. Cipani, C. Tubaro, M. Basato, M. Costante, E. Bressan, A. Venzo and C. Graiff, New J. Chem., 2013, 37, 4176-4184; (b) C. Radloff, H.-Y. Gong, C. Schulte to Brinke, T. Pape, V. M. Lynch, J. L. Sessler and F. E. Hahn, Chem. Eur. J., 2010, 16, 13077-13081.

12 (Scheme 2, A): R. S. Simons, P. Custer, C. A. Tessier and W. J. Youngs, Organometallics, 2003, 22, 1979-1982.

13 (Scheme 2, B): D. J. Nielsen, K. J. Cavell, B. W. Skelton and A. H. White, Inorg. Chim. Acta, 2002, 327, 116-125.

14 (Scheme 2, C and D): T. Nakamura, S. Ogushi, Y. Arikawa and K. Umakoshi, J. Organomet. Chem., 2016, 803, 67-72.

15 (Scheme 2, C): A. Herbst, C. Bronner, P. Dechambenoit and O. S. Wenger, Organometallics, 2013, 32, 1807-1814.

16 (Scheme 2, D): B. R. M. Lake and C. E. Willans, Chem. Eur. J., 2013, 19, 16780-16790; B. Liu, X. Ma, F. Wu and W. Chen, Dalton Trans., 2015, 44, 1836-1844.

17 (Scheme 2, E): D. I. Bezuidenhout, G. Kleinhans, G. Guisado-Barrios, D. C. Liles, G. Ung and G. Bertrand, Chem. Commun., 2014, 50, 2431-2433. 
18 A. V. Knishevitsky, N. I. Korotkikh, A. H. Cowley, J. A. Moore, T. M. Pekhtereva, O. P. Shvaika and G. Reeske, J. Organomet. Chem., 2008, 693, 1405-1411.

19 (a) R. E. Andrew, D. W. Ferdani, C. A. Ohlin and A. B. Chaplin, Organometallics, 2015, 34, 913-917; (b) R. E. Andrew and A. B. Chaplin, Inorg. Chem., 2015, 54, 312-322; (c) R. E. Andrew and A. B. Chaplin, Dalton Trans., 2014, 43, 1413-1423.

20 I. Krossing and I. Raabe, Angew. Chem., Int. Ed., 2004, 43, 2066-2090.

21 D. Tapu, D. A. Dixon and C. Roe, Chem. Rev., 2009, 109, 3385-3407.

22 Related observations have been made for $\mathrm{Ag}(\mathrm{I})$ and $\mathrm{Au}(\mathrm{I})$ complexes of di-NHC ligands: J. Gil-Rubio, V. Cámara, D. Bautista and J. Vicente, Inorg. Chem., 2013, 52, 40714083.

23 Other instances of the $\left[\mathrm{Cu}_{2} \mathrm{Br}_{4}\right]^{2-}$ dianion see: (a) B. R. M. Lake, A. Ariafard and C. E. Willans, Chem. -
Eur. J., 2014, 20, 12729-12733; (b) E. Boess, D. Sureshkumar, A. Sud, C. Wirtz, C. Farès and M. Klussmann, J. Am. Chem. Soc., 2011, 133, 8106-8109; (c) P. Drożdżewski and M. Kubiak, Polyhedron, 2009, 28, 1518-1524; (d) A. J. Canty, L. M. Engelhardt, P. C. Healy, J. D. Kildea, N. J. Minchin and A. H. White, Aust. J. Chem., 1987, 40, 1881-1891.

24 The other independent cation features a significant degree of disorder about the copper centre.

25 V. J. Catalano, L. B. Munro, C. E. Strasser and A. F. Samin, Inorg. Chem., 2011, 50, 8465-8476.

26 (a) C. Chen, H. Qiu and W. Chen, J. Organomet. Chem., 2012, 696, 4166-4172; (b) X. Liu and W. Chen, Organometallics, 2012, 31, 6614-6622.

27 W. E. Buschmann, J. S. Miller, K. Bowman-James and C. N. Miller, Inorg. Synth., 2002, 33, 83-91.

28 J. A. McCleverty, G. Wilkinson, L. G. Lipson, M. L. Maddox and H. D. Kaesz, Inorg. Synth., 1990, 28, 84-86. 